Journal of Mathematics and Informatics

Vol. 14, 2018, 27-33

ISSN: 2349-0632 (P), 2349-0640 (online)

Published 4 September 2018

www.researchmathsci.org

DOI: http://dx.doi.org/10.22457/jmi.v14a4

Journal of

Mathematics and

Informatics

\title{
Effect of User Habits on WeChat Reward Intention
}

\author{
Huan Liu ${ }^{1}$, Jing Liu ${ }^{2}$ and Liang-ru Y $u^{3}$ \\ ${ }^{1}$ School of Economics and Management \\ Chongqing University of Posts and Telecommunications \\ Chongqing - 400065, Chongqing, China. E-mail: sallyhliu@ hotmail.com \\ ${ }^{2}$ Library and Information Center \\ Chongqing Medical and Pharmaceutical College \\ Chongqing - 401331, Chongqing, China. E-mail: 717139038@qq.com \\ ${ }^{3}$ School of Economics and Management \\ Chongqing University of Posts and Telecommunications \\ Chongqing - 400065, Chongqing, China. E-mail: yuliangru@qq.com \\ ${ }^{2}$ Corresponding author
}

Received 8 August 2018; accepted 4 September 2018

\begin{abstract}
We studied the impact of WeChat public platform reading time (WRT) and mobile operating system (MOS) on WeChat reward intention (WRI). The participants included 210 Chinese WeChat users. We found that WRT had a significant positive effect on WRI. Moreover, MOS moderated the relationship between WRT and WRI. That's to say, users of using Android (vs. iOS) whose WRT had a stronger positive effect on their WRI. Our findings indicated that the author of WeChat public platform should recognize how much are the users' WRT and which is the users' MOS, and the author can develop differentiated marketing strategies based on the different users' WRT and MOS.
\end{abstract}

Keywords: user habits; reading time; mobile operating system; WeChat reward; moderating effect

\section{AMS Mathematics Subject Classification (2010): 62P25}

\section{Introduction}

Chinese Internet users' content payment habits are gradually being developed. For example, WeChat users will pay for the article as a reward for the author voluntarily after reading the original article on the WeChat public platform, and this kind of behavior is called WeChat reward. WeChat reward is one kind of special content payment behavior, and the special features are reflected in the difference in payment methods. To the traditional content payment, users should pay money (a fixed price set by the seller) to the author firstly, and then they just can read the entire content of the article. To the WeChat reward, users can read the entire content of the article firstly, and then they may pay money (a price they are willing to pay) to the author. It is necessary to have a study on the influencing factors of WeChat reward due to the particularity of payment methods in WeChat reward. This paper studies the influencing factors of Chinese Internet users' WeChat reward intention (WRI). 
Huan Liu, Jing Liu and Liang-ru Yu

WRI may be influenced by user habits. User habits can affect consumers' purchasing decisions [1]. Different user habits lead to different users' willingness to purchase [2]. Such as, users who have longer reading time (vs. shorter reading time) are more willing to pay for novel, and their willingness to pay for content is higher [3,4]; iOS (vs. Android) users are used to paying for music, and their willingness to pay for content is higher [5]. Therefore, we suspect that user habits will affect WRI.

Relevant literatures have studied the influencing factors of willingness to pay for content, including perceived added value [6], demographic factors [7], perceived value [8], website technical quality [9] and free mindset [10]. There is little literature on the role of user habits in previous literature. This paper studies the impact of users' WeChat usage habits (e.g., WeChat public platform reading time, which abbreviated as WRT) and users' mobile usage habits (e.g., mobile operating system, which abbreviated as MOS) on WRI based on Chinese content payment context (WeChat reward). We try to enrich the existing research from two aspects that content payment's context and antecedent. The research framework of this paper is shown in Figure 1.

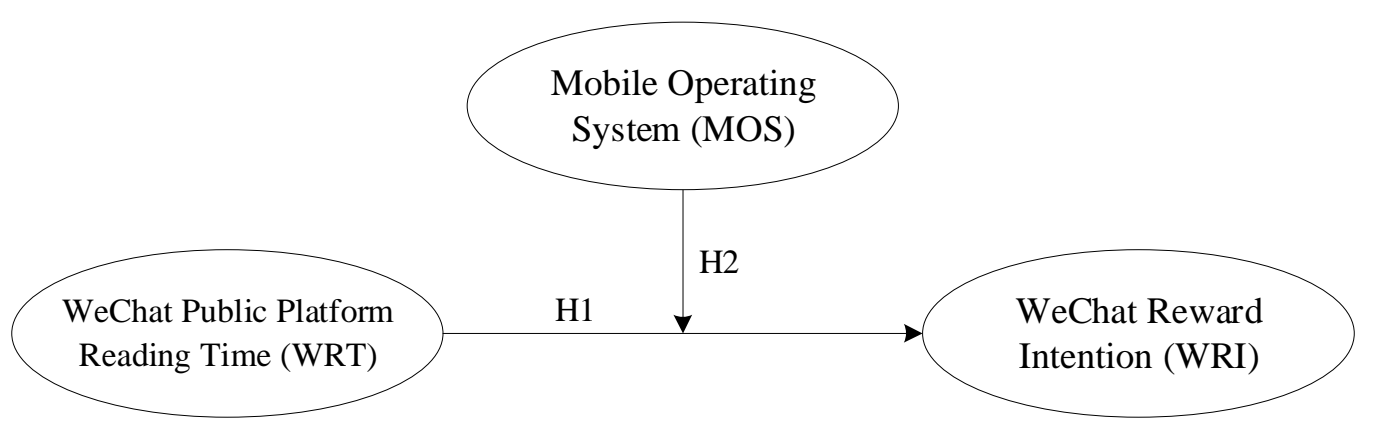

Figure 1: Research framework

\section{Hypotheses}

\subsection{WRT}

Users who have longer (vs. shorter) WRT are used to using WeChat public platform for reading, and they are willing to spend more time reading the content on the WeChat public platform. Furthermore, they also have the ability to search for more information on the WeChat public platform, which can reduce their perceived risk [11]. Perceived risk can reduce the willingness to pay for content [5]. The longer (vs. shorter) users' WRT, the lower their perceived risk, and the higher their WRI. Therefore, this paper proposes the following hypotheses:

\section{H1: WRT will have a positive effect on WRI.}

\subsection{Moderating role of MOS}

The Android and the iOS provide users with different reward page. The Android provides users with a dedicated channel for reward. Android users just click "reward" to enter the reward page immediately. The iOS provides users with a reward code. iOS users need to scan the reward code before they enter the reward page. That's to say, the reward page 
Effect of User Habits on WeChat Reward Intention

provided by the Android (vs. iOS) is easier to use. Previous studies have shown that accessibility can increase the willingness to pay for content [12]. Therefore, MOS may affect the relationship between WRT and WRI. For Android (vs. iOS) users, the positive relationship between WRT and WRI may be stronger. Therefore, this paper proposes the following hypotheses:

H2: MOS will moderate the relationship between WRT and WRI, Android (vs. iOS) users' WRT will have a stronger positive effect on WRI.

\section{Methods}

\subsection{Sample and Procedure}

The sample characteristics were shown in Table 1.

Table 1: Sample characteristics

\begin{tabular}{|c|c|c|c|}
\hline Characteristics & Categories & $\begin{array}{c}\text { Number of } \\
\text { Questionnaires }\end{array}$ & Percentage (\%) \\
\hline \multirow{2}{*}{ Gender } & Male & 86 & 40.95 \\
\hline & Female & 124 & 59.05 \\
\hline \multirow{4}{*}{$\begin{array}{c}\text { Age } \\
\text { (Years) }\end{array}$} & $20-30$ & 93 & 44.29 \\
\hline & $30-40$ & 90 & 42.86 \\
\hline & $40-50$ & 22 & 10.48 \\
\hline & $50-60$ & 5 & 2.38 \\
\hline \multirow{5}{*}{$\begin{array}{c}\text { WRT } \\
\text { (Hours/Day) }\end{array}$} & Below 1 & 77 & 36.67 \\
\hline & $1-2$ & 86 & 40.95 \\
\hline & $2-3$ & 29 & 13.81 \\
\hline & $3-5$ & 16 & 7.62 \\
\hline & Above 5 & 2 & 0.95 \\
\hline \multirow{3}{*}{ Education } & Bachelor Below & 29 & 13.81 \\
\hline & Bachelor & 168 & 80.00 \\
\hline & Master or Above & 13 & 6.19 \\
\hline \multirow{6}{*}{$\begin{array}{c}\text { Income } \\
\text { (CNY/Month) }\end{array}$} & Below 2000 & 1 & 0.48 \\
\hline & $2000-4000$ & 21 & 10.00 \\
\hline & $4000-6000$ & 49 & 23.33 \\
\hline & $6000-8000$ & 76 & 36.19 \\
\hline & $8000-10000$ & 34 & 16.19 \\
\hline & Above 10000 & 29 & 13.81 \\
\hline \multirow{2}{*}{ MOS } & $\mathrm{iOS}$ & 40 & 19.05 \\
\hline & Android & 170 & 80.95 \\
\hline
\end{tabular}


Huan Liu, Jing Liu and Liang-ru Yu

All participants used WeChat (an application with instant messaging, social and payment functions). We cooperated with a professional online survey company that has a sample library of 2.6 million people to obtain the samples which are randomly selected from the sample library by a computer program. And the computer program sent a questionnaire with virtual experimental situations to the selected samples via the way of email and website private message push.

\subsection{Measures}

Dependent variable (WRI). At the beginning of the questionnaire, the participants were asked to imagine: one day, they were working overtime at 23 o 'clock to write a report that must be submitted to their superiors at 8 o 'clock the next day. However, the key parts of the report lacked references. At this point, the participants found an article on the WeChat public platform. The participants found the article was very useful after reading the entire content of the article, and the author of the article gave a link of reward at the end of the article. And then, the participants were asked if they were willing to pay for the article as a reward for the author and the amount they were willing to pay. Among them ,182 participants were willing to pay, and their MRI was set to the amount that they were willing to pay; 28 participants (13.33\%) were unwilling to pay, and their WRI was set to zero. All participants' WRI ranged from CNY 0 to CNY $200(\mathrm{M}=30.40, \mathrm{SD}=$ 40.70).

Independent variable (WRT). We treated it as a continuous variable when processing data.

Moderator variable (MOS). We treated it as a dummy variable when processing data. Moreover, the Android code was 0 , and the iOS code was 1.

Control variable. The control variable including four demographic variables (i.e., gender, age, education, and logarithm of income).

\section{Results}

This paper used regression analysis to test the hypothesis, and the software used was SPSS 23.0. In the regression analysis, we following the common practice that we first decomposed the variable (minus the mean value of the variable) before calculating the cross term of the variable [13]. The results of the regression analysis were shown in Table 2. In the three models of table 2 , the variance inflation factor (VIF) of each variable was far less than 10, indicating that the multicollinearity was not serious and the analysis results were reliable.

Model 1 only contained control variables (i.e., gender, age, education, and logarithm of income). It can be seen from Model 2 that WRT had a significant positive effect on WRI $(\beta=0.223, p<0.01)$. Thus, Hypothesis 1 was supported. Meanwhile, MOS had no significant effect on WRI $(\beta=0.034, p>0.1)$. It can be seen from Model 3 that MOS moderated the relationship between WRT and WRI, and Android (vs. iOS) users' MTR had a stronger positive effect on WRI $(\beta=-0.210, p<0.01)$. Combined with the results of Model 2, we can know that Hypothesis 2 was supported (as shown in Figure 2). 
Effect of User Habits on WeChat Reward Intention

Table 2: Results of regression analysis

\begin{tabular}{|c|c|c|c|}
\hline \multirow{2}{*}{ Variable } & $\begin{array}{c}\text { Model 1 } \\
\text { Control Variable }\end{array}$ & $\begin{array}{c}\text { Model 2 } \\
\text { Main Effect }\end{array}$ & $\begin{array}{c}\text { Model 3 } \\
\text { Moderating Effect }\end{array}$ \\
\hline \multirow{2}{*}{ Gender } & -0.030 & -0.024 & -0.004 \\
& $(-0.404)$ & $(-0.330)$ & $(-0.057)$ \\
\hline \multirow{2}{*}{ Age } & -0.007 & -0.027 & -0.025 \\
& $(-0.091)$ & $(-0.376)$ & $(-0.346)$ \\
\hline \multirow{2}{*}{ Education } & 0.051 & 0.023 & 0.023 \\
& $(0.677)$ & $(0.303)$ & $(0.314)$ \\
\hline \multirow{2}{*}{ Logarithm of Income } & 0.072 & 0.079 & 0.081 \\
& $(0.921)$ & $(1.031)$ & $(1.084)$ \\
\hline \multirow{2}{*}{ WRT } & & $0.223^{* *}$ & $0.287^{* * *}$ \\
& & $(3.239)$ & $(4.051)$ \\
\hline \multirow{2}{*}{ MOS } & & 0.034 & 0.035 \\
& & $(0.489)$ & $(0.514)$ \\
\hline \multirow{2}{*}{ WRT $\times$ MOS } & & & $-0.210^{* *}$ \\
& & & $(-2.986)$ \\
\hline R2 & 0.011 & 0.062 & 0.102 \\
\hline F & 0.545 & $2.231^{*}$ & $3.260^{* *}$ \\
\hline$\square$ R2 & 0.011 & 0.051 & 0.040 \\
\hline F of $\square$ R2 & 0.545 & $5.554^{* *}$ & $8.916^{* *}$ \\
\hline Maximum VIF Value & 1.258 & 1.259 & 1.259 \\
\hline
\end{tabular}

Note. 1) $\mathrm{t}$ value was in parentheses; 2) coefficient had been standardized; 3$) * \mathrm{p}<0.05$, ** $\mathrm{p}<0.01, * * * \mathrm{p}<0.001 ; 4)$ intercept was not listed.

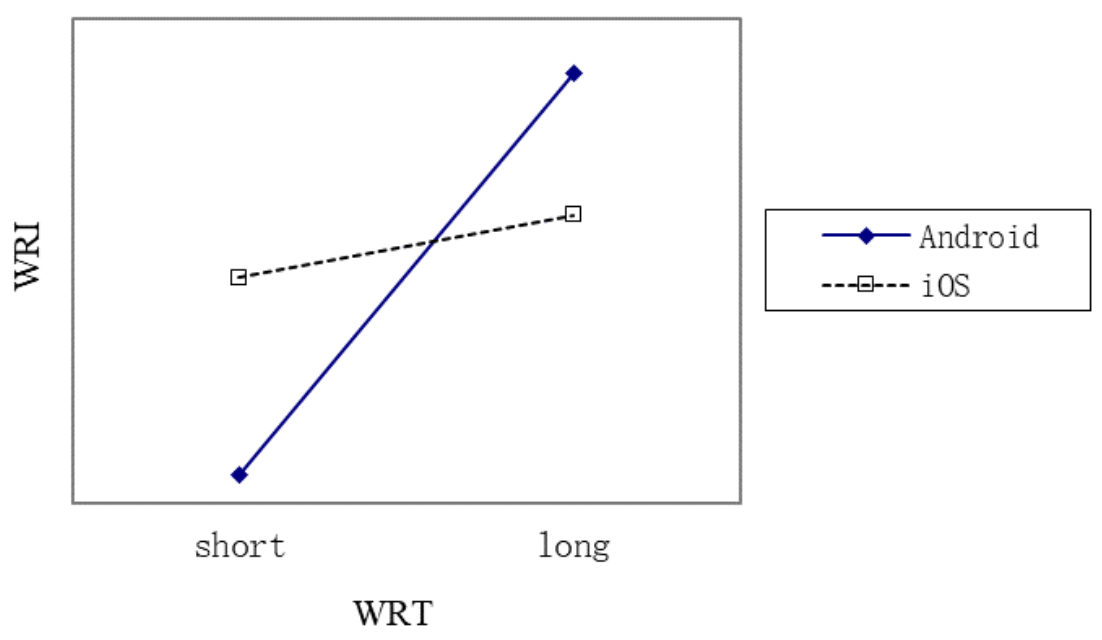

Figure 2: The moderating effect of MOS 
Huan Liu, Jing Liu and Liang-ru Yu

\section{Conclusion}

This paper extends existing research in two ways. 1) This paper expands the research context of willingness to pay for content. This paper study the influencing factors of Chinese Internet users' WRI. WeChat reward is one kind of special content payment behavior (users can read the entire content of the article firstly, and then pay the amount they are willing to pay to the author), so it is necessary to conduct a separate study. There are few literatures about WeChat reward in previous studies. 2) The habit is used as a factor affecting the willingness to pay for content, and we introduce two habit factors that is WRT and MOS. The WRT reflects user's WeChat usage habits, which is the foundation of WeChat reward. The MOS reflects user's mobile phone usage habits. Different MOS provides users with a different reward page, resulting in users' different payment processes. These two types of factors are rarely discussed in detail in previous studies. This paper found that WRT has a significant positive effect on WRI, and MOS moderates the relationship between WRT and WRI. These results complement the study of the willingness to pay for content.

Practical implications of our findings are that help the authors of WeChat public platform and WeChat public platform to design marketing strategy. First, the authors of the WeChat public platform should recognize users whose WRT is longer, and their WRI is higher. Therefore, it is necessary to design marketing campaigns for them specially. The authors of the WeChat public platform can use the WeChat public platform to achieve accurate identification, recommendation and promotion by using the user behavior big data of the platform statistics. Second, the authors of the WeChat public platform should recognize the MOS used by users. In addition, the authors should try to provide a more convenient reward page for iOS users with the help of the backend of WeChat public platform, so as to maximize the reward amount of users.

\section{REFERENCES}

1. E.Turban, D.King, J.Lee, T.P.Liang and D.Turban, Electronic Commerce 2012: A Managerial and Social Networks Perspective, 7th Edition, Pearson, London, 2015.

2. J.S.Chiou and L.Y.Pan, Antecedents of internet retailing loyalty: Differences between heavy versus light shoppers, Journal of Business Psychology, 24(3) (2009) 327-339.

3. P.Korgaonkar and L.D.Wolin, Web usage, advertising, and shopping: Relationship patterns, Internet Research Electronic Networking Applications and Policy, 12(2) (2002) 191-204.

4. B.Wansink and S.B.Park, Methods and measures that profile heavy users, Journal of Advertising Research, 40(4) (2000) 61-72.

5. L.G.Schiffman and J.Wisenblit, Consumer Behavior, Pearson, London, 2014.

6. C.Marta-Lazo, A.Segura-Anaya and N.MartínezOliván, Key variables in willingness to pay for online news content: The professionals' perspective, Revista Latina de Comunicación Social, 72 (2017) 165-185.

7. G.Punj, The relationship between consumer characteristics and willingness to pay for general online content: Implications for content providers considering subscriptionbased business models, Marketing Letters, 26(2) (2015) 175-186. 
Effect of User Habits on WeChat Reward Intention

8. Y.S.Wang, C.H.Yeh and Y.W.Liao, What drives purchase intention in the context of online content services? The moderating role of ethical self-efficacy for online piracy, International Journal of Information Management, 33(1) (2013) 199-208.

9. A.B.Lopes and D.F.Galletta, Consumer perceptions and willingness to pay for intrinsically motivated online content, Journal of Management Information Systems, 23(2) (2006) 203-231.

10. W.Dou, Will internet users pay for online content? Journal of Advertising Research, 44(4) (2004) 349-359.

11. D.Gefen, E.Karahanna and D.W.Straub, Trust and TAM in online shopping: An integrated model, Mis Quarterly, 27(1) (2003) 51-90.

12. J.S.Ilfeld and R.S.Winer, Generating Website Traffic, Journal of Advertising Research, 42(5) (2002) 49-61.

13. L.S.Aiken and S.G.West, Multiple Regression: Testing and Interpreting Interactions. Newbury Park, Sage Publications, California, 1991. 